\title{
PELAYANAN SOSIAL BAGI LANSIA TERLANTAR (Studi di Yayasan Al'Azis Kendari Sulawesi Tenggara)
}

\author{
Irda Suci Ramadhani Nasir ${ }^{1}$, Muh Arsyad ${ }^{2}$, Aryuni Salpiana Jabar ${ }^{3}$ \\ ${ }^{123}$ Universitas Halu Oleo \\ Email: irdasuciramadhani057@gmail.com, muharsyad@gmail.com; aryunijabar@gmail.com
}

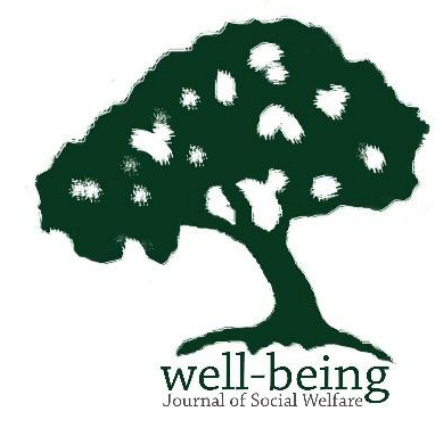

\section{ABSTRAK}

\begin{abstract}
This type of research used in this research is descriptive qualitative research with data collection techniques, interviews, observation, and documentation. While the informants in this study were the Chairperson of the Foundation, Secretary, Elderly associate, and abandoned elderly. The results of this study show that the existence of the Al'azis Foundation provides increased welfare for the abandoned elderly people such as the existence of Home Care Assistance Services and Elderly Social Care at home and Day Care and Elderly Posyandu which aims to improve the ability of the elderly productive or even non-productive ones. While, for the factors that affect the quality of elderly social services with the fulfillment of human resources and the infrastructure for the services provided as well as organized management and cooperation/partners undertaken which to produce mutual benefits.
\end{abstract}

Keywords: Social services, Abandoned Elderly, Al 'Azis Foundation

\section{PENDAHULUAN}

Lansia terlantar adalah seseorang yang berusia 60 tahun atau lebih karena faktor-faktor tertentu tidak dapat memenuhi kebutuhan dasarnya baik secara jasmani, rohani, maupun sosialnya. Lansia terlantar adalah mereka yang tidak memiliki sanak saudara, atau punya sanak saudara tapi tidak mau mengurusinya. Proses menua merupakan proses yang terus menerus (berlanjut) secara alamiah dimulai sejak lahir dan umumnya dialami pada semua makhluk hidup.Menua (menjadi tua) adalah suatu proses menghilangnya secara perlahan lahan kemampuan jaringan untuk memperbaiki diri atau mengganti dan mempertahankan fungsi normalnya sehingga tidak dapat bertahan terhadap infeksi dan memperbaiki kerusakan yang diderita.Semua orang akan mengalami proses menjadi tua dan masa tua merupakan masa hidup manusia yang terakhir, yang pada masa ini seseorang mengalami kemunduran fisik, mental dan sosial sedikit sampai tidak memerlukan tugasnya sehari-hari lagi hingga bagi kebanyakan orang masa tua itu merupakan masa yang kurang menyenangkan.

Observasi awal yang peneliti lakukan dengan melihat kondisi lansia yang dimana lansia tinggal sendiri dan tidak memiliki teman sama sekali, karena kondisinya terkadang mengingatkan masa lalu lansia, dalam hal ini lansia tidak bisa berkomunikasi dengan baik dan benar. Dalam kesehariannya lansia hanya mulung di sekitar tempat tinggalnya dan biasa juga si lansia mulung sampai tidak pulang hanya untuk mulung untuk mendapatkan uang untuk kesehariannya. Sebuah yayasan berkunjung di kampung pemulung untuk membawa sebuah bingkisan dan melihat lansia yang kehidupannya sangat memprihartinkan lalu pihak yayasan tertarik untuk menangani lansia tersebut dan diberikan pelayanan sebagaimana yang dapat diberikan oleh yayasan tersebut sehingga si lansia dapat mengurangi sedikit demi sedikit pekerjaan yang dilakukannya untuk terpenuhi kebutuhan sehari-harinya. Ada beberapa pelayanan sosial bagi lansia terlantar yang diprogramkan yang diantaranya adalah home car, day car, dan 
posyandu lansia . Serta ada beberapa faktor yang menunjang kualitas pelayanan lansia tersebut diantaranya sumber daya manusia, sarana dan prasaran, pengelolaan dan kerja sama/mitra . Dari adanya pendataan dari KTP ataupun Kartu Keluarga yang dilakukan yayasan baik yang sudah dilakukannya observasi dan rujukan dari kelurahan dan masyarakat setempat kurang lebih 200 lansia yang terbagi atas dua kategori yaitu kategori lansia tidak terlantar dan lansia terlantar yang sudah menjadi pertimbangan yayasan akan diberikan pelayanan berdasarkan kemampuan dan kondisi lansia tersebut .

\section{METODE PENELITIAN}

Penelitian ini dilakukan Di Yayasan Al'Azis Kendari Sulawesi Tenggara, peneliti mengambil penelitian ini dengan alasan lansia terlantar di Kota Kendari ini cukup banyak. Pertimbangan lain bahwa peneliti ingin mengetahui bagaimana kah pelayanan lansia terlantar dan faktor-faktor apa saja kah yang memperngaruhi kualitas pelayanan lansia terlantar Di Yayasan Al'Azis Kendari, Sulawesi tenggara. Tipe penelitian ini adalah Deskriptif kualitatif salah satu jenis penelitian yang tujuannya untuk menyajikan gambaran lengkap mengenai setiting sosial atau dimaksudkan untuk eksplorasi dan klarifikasi mengenai suatu fenomena atau kenyataan sosial . Teknik pengambilan informan dalam penelitian ini yakni menggunkan informan kunci (key informan) yang ditentukan secara langsung, adapun informan kunci dalam penelitian ini yaitu kepala Yayasan Al'Azis Kendari Sulawesi Tenggara dan informan tambahan yaitu 1 sekertari 2 pendamping dan 2 lansia terlantar. Metode pengumpulan data yang digunakan dalam penelitian ini terdiri wawancara, observasi dan dokumentasi.Analisis data yang dipergunakan dalam penelitian ini adalah analisis deskriptif, artinya analisis data yang bukan menggunakan angka-angka melainkan dalam bentuk kata-kata, kalimat ataupun paragraf yang dinyatakan dalam bentuk deskriptif.Adapun langkah-langkah peneliti dalam menganalisis data sebagaimana dijelaskan oleh Sugiyono (2005) adalah: Reduksi data, penyajian data, dan penarikan kesimpulan.

\section{HASIL DAN PEMBAHASAN}

Yayasan Al'Azis Kendari merupakan yayasan yang berada di lingkungan kelurahan Mandonga kecamatan Mandonga, dimana Yayasan tersebut berada di tengah-tengah perkotaan yang ada di Kota Kendari. Adapun yang melatarbelakangi pendirian Yayasan tersebut adalah dimulai dari kegiatan Posyandu Lansia yang yang merupakan kegiatan rutin yang dilaksanakan di Yayasan Al'Azis Kendari setiap tanggal 16 tiap bulannya. Dimana Pendiri yayasan Al'Azis kendari adalah Ibu Sitti Ariyani Azis yang lahir di Kendari, 3 maret 1942 (usia 77tahun) dimana beliau adalah Ibu dari 10 (sepuluh ) orang anak, terdiri dari 6(enam) anak laki-laki dan 4 (empat) anak perempuan. Serta memiliki 10 (sepuluh) menantudan 24 (dua puluh empat) cucu. Dari beberapa hal tersebut di atas, maka terbersit pikiran Ibu Siiti Ariyani Azis untuk membentuk satu lembaga yang bergerak di bidang social kemasyarakatan dimana salah satu tujuannya untuk membantu para lansia dalam meringankan bebannya utamanya untuk membantu lansia dalam upaya pendampingan dan perawatan. Adapun Pembina Yayasan Al'Azis adalah Ibu Sitti Ariyani Azis, penanggung jawab Yayasan Al'Azis adalah Ibu Sitti Asnany Azis, SE dan alamat secretariat terletak di Jalan Laute (Lrg ADB) No.9 C RT.001 RW 003 Kelurahan Mandonga, Kecamatan Mandonga Kota Kendari Provinsi Sulawesi Tenggara. Adapun sarana prasarana adalah sebuah sekretariat yang berlokasi di jalan Laute (lrgADB ) No.9 C Mandonga, seperangkat computer dan print, ruang kerja dan seperangkat kursi tamu 
dilengkapi dengan meja penyimpanan arsip dan dokumen dan beberapa perlengkapan lainnya.

Tabel 1 Data lansia Yayasan Al'Azis

Kendari Sulawesi Tenggara

\begin{tabular}{|c|c|c|}
\hline No & Jenis Kelamin & Jumlah \\
\hline 1 & Laki-Laki & 75 \\
\hline 2 & Perempuan & 125 \\
\hline & Total & 200 \\
\hline
\end{tabular}

\section{Pelayanan Sosial Bagi Lansia Terlantar}

Pelayanan sosial yang dimaksud adalah pelayanan yang ditujukan kepada lansia yang non produktif dan produktif yang bertujuan untuk menjalankan keberfungsian sosial lansia tersebut agar dapat menjalankan kehidupannya dengan bermanfaat dan mandiri .

\section{a. Pendampingan Dan Perawatan Sosial Lanjut Usia Di Rumah(Home Care)}

Pendampingan Dan Perawatan Sosial Lanjut Usia Di Rumah(Home Care) adalah suatu pelayanan sosial yang dilakukan di rumah untuk menunjang kesehatan lansia yang non produktif untuk membantu keberfungsian lansia itu sendiri dalam hal ini lansia yang non produktif di berikan pelayanan selayaknya yang ia butuhkan seperti perawatan jalan dan bantuan sembako

\section{b. Pelayanan Harian Lanjut usia (Day Care)}

Pelayanan Harian Lanjut usia (Day Care) pelayanan sosial lanjut usia yang isi atau pelyanannya bertujuan untuk membangun fisik lansia agar dapat menjalankan keberfungsiannya dengan sebagaimana mestinya, menjalin komunikasi dengan baik antar sesamanya, melatih keterampian lansia agar dapat menpunyai kemandirian dan tidak merasa bosan . pelayanan ini juga tidak lebih dari waktu yang ditentukan dikarenakan adanya rasa bosan dan jenuh pada lansia.

\section{c. Posyandu Lansia}

Posyandu lansia adalah pelayanan kesehatan yang dilakukan secara berkala yang tujuannya untuk memeriksa kesehatan lansia yang menderita sakit untuk ditindak lanjuti, pelayanan ini bukan dilakukan di rumah sakit maupun pelyanan ini dilakukan disuatu organisasi atau yayasan yang berwenang untuk melakukan pelyanan ini karena tidak banyaknya organisasi atau yayasan yang mempunyai pelayanan seperti posyandu lansia ini . yayasan al'azis kendari sulawesi tenggara adalah yayasan yang mempunyai program posyandu lansia ini karena banyaknya tingkat lansia yang produktif dan non produktif yang kurang mampu untuk berobat di rumah sakit

2. Faktor-Faktor Yang mempengaruhi Kualitas Pelayanan Sosial Lansia Terlantar

Faktor-faktor pelayanan yang menunjang kualitas pelayanan sosial di yayasan al'azis ini berupa sember daya manusia yang memadai untuk menunjang kegiatan-kegiatan yang sudah terstuktur dan sudah pada porsinya msing-masing , sarana dan prasarana yang mendukung pelayanan, peraturan pengelolaan yang tertata dengan baik serta kerja sama/mitra yang luas .

\section{a. Sumber Daya Manusia}

Manajemen sumber daya manusia adalah individu produktif yang bekerja sebagai penggerak suatu organisasi, baik itu didalam institusi maupun perusahaan yang memiliki fungsi sebagai aset 
sehingga harus dilatih dan dikembangkan kemampuannya.

b. Sarana Dan Prasarana

Sarana merupakan falilitas yang dipakai secara langsung (utama), sedangkan prasarana merupakan fasilitas penunjang dari sarana. Sarana adalah segala sesuatu yang dapat dipakai sebagai alat dalam mencapai maksud atau tujuan, sedangkan prasarana adalah segala sesuatu yang menunjang terselenggaranya suatu proses tersebut. Sarana dan prasarana yang dibutuhkan untuk pelayanan dan program yang akan dilaksanakan serta sarana yang dibutuhkan oleh lansia untuk ikut serta dalam program pelayanan yang sudah ada untuk menunjang peyanan untuk para lansia yang produktif dan non produktif .

c. Peraturan Pengelola

Peraturan adalah ketentuanketentuan yang harus dilaksanakan dalam suatu daerah atau suatu instansi. Sedangkan pengelola adalah orang yang mengelola suatu daerah atau instansi. Pengelolaan yayasan al'azis dikelolah oleh bendahara yang disetujui oleh penanggung jawab yayasan ataupun ketua yayasan yang berwenang mengetahui segala hal yang dilakukan oleh yayasan tersebut baik soal pengelolaan kegiatan keuangan maupun yang lainnya pengelolaan yayasan al'azis terstruktur dengan baik dengan tugas-yang sudah di bagi masingmasing

\section{d. Kerja Sama/ Mitra}

Mitra adalahmitra dalam melakukan sebuah usaha kerja sama untuk mencapai suatu tujuan yang berdasar pada suatu kesepakatan dan peran masing-masing.Kerja sama yang dilakukan Yaysan Al'azis Kendari Sulawesi Tenggara yaitu dengan bekerjasama langgsung oleh kementrian sosial pusat maupun provinsi dan kota selain itu kerja sama atau mitra yang terdekat yaitu dengan loka rehabilitasi sosial lanjut usia minaula kendari yang biasa melakukkan kunjungan atau membuat kegiatan yang melibatkan lansia maupun keluarga lansia dengan mendapatkan mareri dukungan keluarga tersebut, selain itu yayasan al'azis juga bermitra dengan puskesmas kadia beserta tenaga medis yang di kepalai oleh Dr.Nicolas Duma Salombe M.Kes dengan kegiatan atau program posyandu lansia yang biasa dilaksanakan sebulan sekali setiap tanggal 16 .

\section{KESIMPULAN}

Pendampingan dan Perawatan Sosial Lanjut Usia Di Rumah (Home Care) Pelayanan kesehatan yang berkesinambungan dan komprehensif yang di berikan kepada individu. Pelayanan Harian Lanjut Usia (Day Care) pelayanan harian atau day care adalah sebuah model program pelayanan sosial untuk lanjut usia bersifat sementara dan dilaksanakan di dalam atau diluar panti dalam waktu tertentu (maksimal 8 jam) tidak menginap yang dikelola oleh pemerintah atau masyarakat secara professional. Posyandu adalah suatu kegiatan masyarakat dalam upaya pelayanan kesehatan pada lanjut usia. Posyandu sebagai suatu wadah kegiatan yang bernuansa pemberdayaan masyarakat akan berjalan baik dan optimal apabila proses kepemimpian, terjadi proses pengorganisasian. Sumber daya manusia Yayasan Al'azis masih sangat membutuhkan staf dalam melakukan sebuah pelayanan yang ahli dalam bidang 
yang sudah ditentukan di karenakan lansia masih sangat butuh pelayanan yang sesuai dengan keluhan atau masalah yang di hadapinya saat ini Sarana dan Prasarana dalam hal ini sarana dan prasarana yag berada di Yayasan Al Aziz yang masih sangat kurang karena banyaknya lansia yang sudah tidak produktif lagi yang kurang bisa mengikuti pelayanan seperti posyandu lansia. Peraturan pengelolaan Yayasan Al'azis ini dipercayakan oleh bendahara untuk dikelolah sebagaimana baiknya dan diperuntukan untuk kegiatan dan program, dimana juga pengelolaan pelayanan pengelolaan untuk lansia harus memenuhi kriteria dan persyaratan seperti mempunyai ktp atau kartu keluarga untuk dasar pengenalan agar dapat dikelola untuk pelayananan selanjutnya .

Kerja sama/Mitra Yayasan Al'Azis

kendari sulawesi tenggara cukup mempunyai Kerja sama/Mitra yang luas seperti kegiatan pelayanan home care, day care, dan posyandu lansia yang berkerjasama dengan dinas sosial kota kendari, dinas sosial provinsi sulawesi tenggara, loka rehabilitasi sosial lanjut usia minaula kendari, serta puskesmas kadia.

\section{DAFTAR PUSTAKA}

Pedoman pendampingan dan perawatan sosial lanjut usia di rumah (home care)

Pedoman pelayanan harian lanjut usia (day care)

Sugiyono. 2005. Memahami Penelitian Kualitatif. Bandung. Alfabeta.

http://prastikanala.blogspot.com/2011/09/ konsep-home-care.html

https://id.wikipedia.org/wiki/Sumber_daya _manusia

https://www.asikbelajar.com/pengertiankedudukan-dan-fungsi-kerjasama/ 